\title{
EDITORIAL
}

\section{Particulate matter, science and EU policy}

\author{
I. Annesi-Maesano*,\#, F. Forastiere ", N. Kunzli ${ }^{+}$and B. Brunekref ${ }^{\S}$, on behalf of the Environment and \\ Health Committee of the European Respiratory Society
}

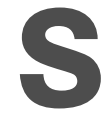
everal new research findings regarding the health effects of airborne particulate matter (PM) (usually studied by the size of the particles, e.g. PM10, particles with a $50 \%$ cut-off aerodynamic diameter of $10 \mu \mathrm{m}$, and PM2.5, particles with a 50\% cut-off aerodynamic diameter of $2.5 \mu \mathrm{m}$ ) have been presented at two important scientific meetings held in September 2006: the Conference of the European Respiratory Society (ERS), in Munich, and the joint Conference of the International Society for Environmental Epidemiology (ISEE) and the International Society for Exposure Analysis (ISEA) in Paris. This is not surprising, since: 1) the health effects of air pollution are among the largest environmental problems worldwide [1]; 2) several scientific questions are still open; and 3) common research efforts from the epidemiological, toxicological and clinical worlds are under way.

\section{SCIENTIFIC EVIDENCE}

A brief review of the evidence follows. The initial suggestion that mortality increases due to long-term, low-level exposure to PM was provided by the Harvard Six Cities study [2]. These findings were confirmed in the long-term follow-up (19821998) of the American Cancer Society (ACS) II cohort, consisting of $\sim 500,000$ adults from metropolitan areas throughout the USA $[3,4]$. In the latter study, each $10 \mu \mathrm{g} \cdot \mathrm{m}^{-3}$ elevation in PM2.5 was associated with approximately a 6, 9 and $14 \%$ increased risk of all-cause, cardiopulmonary and lung cancer mortality, respectively. A recent report from Los Angeles [5], which included a large proportion of the ACS II cohort from that area, has indicated that a more refined method for assessing exposure produces a higher risk estimate of mortality increase (17\% increase; $95 \%$ confidence interval 5 $30 \%$ ) for an increase of $10 \mu \mathrm{g} \cdot \mathrm{m}^{-3}$ in PM2.5. Well-conducted cohort studies in Europe, which have estimated air pollution exposure at individual residences, confirm the findings from the USA and indicate that air pollution emitted from road traffic, including PM, is of greatest concern [6-8]. The evidence of chronic effects has also accumulated for morbidity data, which indicate that the respiratory effects of long-term

*Epidemiology of Allergic and Respiratory Diseases (EPAR) Dept, INSERM U707, "EPAR Dept, UMR-S 707 UPMC Paris 6, Paris, France. "Dept of Epidemiology, Rome E Health Authority, Rome, Italy. ${ }^{+}$Center for Research in Environmental Epidemiology (CREAL), Institut Municipal d'Investigació Mèdica (IMIM), Barcelona, Spain. ${ }^{\S}$ Institute for Risk Assessment Sciences, Universiteit Utrecht, Utrecht, The Netherlands.

STATEMENT OF INTEREST: None declared.

CORRESPONDENCE: I. Annesi-Maesano, Epidemiology of Allergic and Respiratory Diseases (EPAR) Dept, UMR-S 707 INSERM and UPMC Paris 6, Medical School Saint Antoine, 27 rue Chaligny, 75571 Paris CEDEX 12, France. Fax: 33 147738454. E-mail: annesi@u707.jussieu.fr exposure include a decrease in lung function and signs of atherosclerosis progression [9-12]. Mortality cohort studies from Europe have not yet been able to study PM2.5 directly but European Union (EU)-funded studies have demonstrated that the correlation between PM2.5 and pollutants shown to be associated with mortality is high [13].

Scientific evidence of the health effects of particulate air pollution is not limited to studies of long-term exposure. In several cities throughout the world, consistent associations have emerged between daily mortality and ambient concentration of PM during the same or the previous few days. The results of two collaborative projects conducted in 90 cities in the USA (National Morbidity Mortality Air Pollution Study; NMMAPS) and in 29 cities in Europe (Air Pollution Health Effects Approach; APHEA-II) have been reported. In the American cities, where annual average concentrations of PM10 ranged $23-46 \mu \mathrm{g} \cdot \mathrm{m}^{-3}$, a $0.27 \%$ increase in total mortality and a $0.69 \%$ increase in cardiorespiratory mortality were detected for a $10 \mu \mathrm{g} \cdot \mathrm{m}^{-3}$ increase in PM10 [14]. There was no evidence of a threshold and the effects were linear even at low levels of concentration. In the European study, based on the most extensive database available in Europe and covering a large range of PM10 concentrations, the risk estimate for overall mortality was $0.6 \%$ per increase of $10 \mu \mathrm{g} \cdot \mathrm{m}^{-3}$ in PM10 [15] and was $0.76 \%$ per $10 \mu \mathrm{g} \cdot \mathrm{m}^{-3}$ PM10 for cardiovascular mortality [16]. Also in Europe, large national studies are available from Spain [17], the Netherlands [18], France [19] and Italy [20] showing similar results.

Short-term effects on respiratory diseases have been detected in both children and adults [21]. However, recent evidence has indicated that the effects on the cardiovascular system are of key importance and that the involvement of the heart may be particularly important in the risk of death associated with air pollution among chronic obstructive pulmonary disease (COPD) patients. Recent studies have shown that sudden cardiac death and myocardial infarction could be triggered by particulate air pollution in the general population [22-24] and among people who have already suffered a myocardial infarction [25].

Thus, the science regarding the health effects of PM is evolving rapidly. A comprehensive and detailed review was published in June 2006 [26] and, quite recently, more papers appeared on the subject of long-term respiratory effects among children [27, 28], adult mortality [29], myocardial infarction [30] and COPD [31]. In addition, research on short-term effects is progressing, with indication of an effect on heart failure [32], arrhythmia [33] and stroke [34], together with evidence of socioeconomic differences in PM-related mortality [35]. 
Experimental research into the understanding of the mechanisms that underlie the observed effects of PM and other pollutants has also rapidly progressed in recent years. While details of the pathophysiological mechanisms remain to be elucidated, numerous experimental models confirm that PM and other oxidant pollutants interfere with a range of mechanisms that are relevant for the observed pathologies. In particular, oxidative stress and inflammatory responses in the respiratory system along with consecutive systemic inflammatory responses have been described in several studies. Moreover, endothelial dysfunction, oxidation of lipids, vascular inflammation, induction of a pro-thrombotic state, as well as interactions with the autonomic function, may explain in particular the various cardiovascular effects associated with ambient air pollution and that the established oxidative and genotoxic effects of PM (particularly PM from diesel engines) are in line with observed associations between air pollution and lung cancer rates [36].

Finally, evidence is accumulating on the most critical issue: are there benefits of exposure reduction? Studies in Dublin, Ireland [37], Switzerland [38] and Germany [39, 40] show that reductions in air pollution and PM are clearly associated with a reduction in health effects. A recent report from the USA indicated that mortality from natural causes decreased following reductions in PM2.5 concentration; these observations came from the Harvard Six Cities study that originally suggested the chronic effects of air pollution [41]. In the 11 countries that collaborate within the European APHEIS Network [42], a reduction to a yearly average concentration of PM2.5 of $15 \mu \mathrm{g} \cdot \mathrm{m}^{-3}$ would result in life expectancy gains, at age $30 \mathrm{yrs}$, of 1 month to $>2$ yrs [43]. At the EU level, with its 450 million inhabitants, the stakes are even greater. The benefits of more stringent PM standards to both general and susceptible populations would be large [44]. Although implementing more stringent air pollution legislation requires more resources, detailed cost-benefit calculations commissioned by the EU have shown that health benefits gained from reduction of PM2.5 in Europe clearly outweigh these costs.

\section{IGNORANCE OF EVIDENCE}

Because scientific results provide such clear messages on the dangers of PM and the benefits of reducing exposure, it is natural to believe that public health measures should be adopted in order to achieve adequate protection of the exposed population. The recent document updating the World Health Organization (WHO) Air Quality Guidelines [1] provides strong scientific support for policy and a general framework to promulgate air pollution standards in both the developed and underdeveloped world. The long-term air quality guideline for PM2.5 has been set to $10 \mu \mathrm{g} \cdot \mathrm{m}^{-3}$.

Unfortunately, the interplay between science, public health needs and actual policy measures is not without difficulties. Europe is facing a transition regarding legislation on air pollution and PM. Several European scientists have publicly expressed their concerns regarding some measures foreseen by the proposed EU directive on air quality, published on September 21, 2005 [45]. In addition, the ERS has released a position paper regarding the drafted new directive [45] with concerns about the proposed limit value for PM2.5 and about the proposed changes to already existing regulations regarding PM10. Briefly, the main concerns are as follows.
1) Neither the proposed PM2.5 "cap" annual average of $25 \mu \mathrm{g} \cdot \mathrm{m}^{-3}$ nor the target value proposed by the EU Parliament on September 26, $2006\left(20 \mu \mathrm{g} \cdot \mathrm{m}^{-3}\right)$ are sufficient to adequately protect public health. The proposed directive recognises the importance of fine particulate matter and that major adverse effects on health occur in Europe today as a consequence of current exposure to PM2.5. The proposed directive indicates that over the next $15 \mathrm{yrs}$, all EU member states should reduce their PM2.5 concentrations by $\geqslant 20 \%$ unless their average level is $<7 \mu \mathrm{g} \cdot \mathrm{m}^{-3}$. However, the "exposure reduction" plans in the proposed directive will not be legally binding. The target value being proposed is a cap of an annual average PM2.5 concentration of $\mu \mathrm{g} \cdot \mathrm{m}^{-3}$ in 2015 (EU Parliament). This level has been associated with very significant adverse health effects, as documented by studies conducted in Europe and elsewhere. The concern is that the net effect of this directive will be that most member states will no longer be stimulated to take exposure reduction measures, as they are already at or below the $20-25 \mu \mathrm{g} \cdot \mathrm{m}^{-3}$ cap. The legally binding annual mean standard in the USA and California is set at 15 and $12 \mu \mathrm{g} \cdot \mathrm{m}^{-3}$, respectively.

2) The exclusion of all "natural" PM from compliance considerations in effect reduces the public health protection from PM10. The European Commission proposes to allow member states to subtract all natural PM from compliance considerations. However, the existing limit values for PM10 (according to the $1999 \mathrm{EU}$ directive [46]) are based on scientific findings regarding the exposure-response relationships of the health effects of particles in ambient air. These relationships have always included the "natural background" as it reflects the real, health-damaging concentrations affecting people. Conversely, the scientific evidence is not reassuring about the short-term health effects of coarse particles on the respiratory system [47]. This new proposal would allow for higher PM10 values than expressed in the existing legislation and therefore weaken health protection.

3) New derogations for PM10 attainment values reduce the public health protection from PM10. The European Commission's proposal introduces new derogation possibilities that would allow member states to delay reaching the legally binding limit values by up to 5 yrs. This would apply to the limit values that already entered into force in 2005 (for PM10 levels) as well as to the limit values which are to enter into force in 2010 (PM2.5). In line with this weakening of proposals, the EU Parliament adopted an annual limit value of $33 \mu \mathrm{g} \cdot \mathrm{m}^{-3}$ from 2010 (1999 EU directive: $20 \mu \mathrm{g} \cdot \mathrm{m}^{-3}$ as of 2010 [46]), with the unfortunate amendment to allow countries exceedance of the daily limits $\left(50 \mu \mathrm{g} \cdot \mathrm{m}^{-3}\right)$ on 55 days $\cdot \mathrm{yr}^{-1}$ (7 days $\cdot \mathrm{yr}^{-1}$ from 2010, according to the 1999 EU directive [46]). The current authors acknowledge that in the real world the limit values may be hard to reach in the short term in some areas in Europe. However, it seems likely that weakening the already agreed and adopted air quality legislation will contribute to an erosion of the credibility of the EU in firm implementation of legislation.

In conclusion, the proposed directive does not adequately reflect the best scientific evidence. In the face of the extensive evidence regarding the effects of particulate matter on health, the American Thoracic Society and other health organisations 
have also recommended promulgation of National Ambient Air Quality Standards (NAAQS) for particulate matter which protect public health with "an adequate margin of safety" [48]. If the proposed directive is approved in its present form, a reduction of the health impacts of air pollution in Europe will be unattainable.

\section{ACKNOWLEDGEMENTS}

Members of the Environment and Health Committee of the European Respiratory Society are: T. Sigsgaard (Aarhus, Denmark); J. Pekkanen (Kuopio, Finland); I. Annesi-Maesano (Paris, France); W. Kreyling (Munich, Germany); F. Forastiere (Head; Rome, Italy); B. Brunekreef (Utrecht, the Netherlands); P. Bakke (Bergen, Norway); N. Kunzli and J. Sunyer (both Barcelona, Spain); J.G. Ayres, P.J. Helms (both Aberdeen) and K. Donaldson (Edinburgh, all UK); B. Forsberg (Umeå, Sweden).

\section{REFERENCES}

1 World Health Organization. WHO air quality guidelines global updates 2005. www.euro.who.int/Document/ E87950.pdf. Date last accessed: December 2006.

2 Dockery DW, Pope CA 3rd, Xu X, et al. An association between air pollution and mortality in six U.S. cities. $N$ Engl J Med 1993; 329: 1753-1759.

3 Pope CA 3rd, Burnett RT, Thun MJ, et al. Lung cancer, cardiopulmonary mortality, and long-term exposure to fine particulate air pollution. JAMA 2002; 287: 1132-1141.

4 Pope CA 3rd, Thun MJ, Namboodiri MM, et al. Particulate air pollution as a predictor of mortality in a prospective study of U.S. adults. Am J Respir Crit Care Med 1995; 151: 669-674.

5 Jerrett M, Burnett RT, Ma R, et al. Spatial analysis of air pollution and mortality in Los Angeles. Epidemiology 2005; 16: 727-736.

6 Hoek G, Brunekreef B, Goldbohm S, Fischer P, van den Brandt PA. Association between mortality and indicators of traffic-related air pollution in the Netherlands: a cohort study. Lancet 2002; 360: 1203-1209.

7 Nafstad P, Haheim LL, Wisloff T, et al. Urban air pollution and mortality in a cohort of Norwegian men. Environ Health Perspect 2004; 112: 610-615.

8 Filleul L, Rondeau V, Vandentorren S, et al. Twenty five year mortality and air pollution: results from the French PAARC survey. Occup Environ Med 2005; 62: 453-460.

9 Brauer M, Hoek G, Van Vliet P, et al. Air pollution from traffic and the development of respiratory infections and asthmatic and allergic symptoms in children. Am J Respir Crit Care Med 2002; 166: 1092-1098.

10 Janssen NA, Brunekreef B, van Vliet $\mathrm{P}$, et al. The relationship between air pollution from heavy traffic and allergic sensitization, bronchial hyperresponsiveness, and respiratory symptoms in Dutch schoolchildren. Environ Health Perspect 2003; 111: 1512-1518.

11 Pénard-Morand C, Charpin D, Raherison C, et al. Longterm exposure to background air pollution related to respiratory and allergic health in schoolchildren. Clin Exp Allergy 2005; 35: 1279-1287.
12 Kunzli N, Jerrett M, Mack WJ, et al. Ambient air pollution and atherosclerosis in Los Angeles. Environ Health Perspect 2005; 113: 201-206.

13 Lewne M, Cyrys J, Meliefste K, et al. Spatial variation in nitrogen dioxide in three European areas. Sci Total Environ 2004; 332: 217-230.

14 Dominici F, Burnett RT. Risk models for particulate air pollution. J Toxicol Environ Health A 2003; 66: 1883-1889.

15 Katsouyanni K, Touloumi G, Samoli E, et al. Confounding and effect modification in the short-term effects of ambient particles on total mortality: results from 29 European cities within the APHEA2 project. Epidemiology 2001; 12: 521-531.

16 Analitis A, Katsouyanni K, Dimakopoulou K, et al. Shortterm effects of ambient particles on cardiovascular and respiratory mortality. Epidemiology 2006; 17: 230-233.

17 Ballester F, Saez M, Perez-Hoyos S, et al. The EMECAM project: a multicentre study on air pollution and mortality in Spain: combined results for particulates and for sulfur dioxide. Occup Environ Med 2002; 59: 300-308.

18 Hoek G, Brunekreef B, Verhoeff A, van Wijnen J, Fischer P. Daily mortality and air pollution in The Netherlands. J Air Waste Manag Assoc 2000; 50: 1380-1389.

19 Zeghnoun A, Eilstein D, Saviuc P, et al. Surveillance des effets à court terme de la pollution atmosphérique sur la mortalité en milieu urbain. Résultats d'une etude de faisabilité dans 9 villes françaises. [Monitoring of shortterm effects of urban air pollution on mortality. Results of a pilot study in 9 French cities.]. Rev Epidemiol Sante Publique 2001; 49: 3-12.

20 Biggeri A, Bellini P, Terracini B, the Italian MISA Group. Metanalisi italiana degli studi sugli effetti acuti dell'inquinamento atmosferico. [Meta-analysis of the Italian studies on the health effects of air pollution.]. Epidemiol Prev 2001; 25: 1-71.

21 Brunekreef B, Holgate ST. Air pollution and health. Lancet 2002; 360: 1233-1242.

22 Peters A, Dockery DW, Muller JE, Mittleman MA. Increased particulate air pollution and the triggering of myocardial infarction. Circulation 2001; 103: 2810-2815.

23 Peters A, von Klot S, Heier M, et al., Cooperative Health Research in the Region of Augsburg Study Group. Exposure to traffic and the onset of myocardial infarction. N Engl J Med 2004; 351: 1721-1730.

24 Forastiere F, Stafoggia M, Picciotto S, et al. A case-crossover analysis of out-of-hospital coronary deaths and air pollution in Rome, Italy. Am J Respir Crit Care Med 2005; 172: 1549-1555.

25 von Klot S, Peters A, Aalto P, et al., Health Effects of Particles on Susceptible Subpopulations (HEAPSS) Study Group. Ambient air pollution is associated with increased risk of hospital cardiac readmissions of myocardial infarction survivors in five European cities. Circulation 2005;112:3073-3079. Erratum in: Circulation 2006; 113: e71.

26 Pope CA 3rd, Dockery DW. Health effects of fine particulate air pollution: lines that connect. J Air Waste Manag Assoc 2006; 56: 709-742.

27 Kulkarni N, Pierse N, Rushton L, Grigg J. Carbon in airway macrophages and lung function in children. N Engl J Med 2006; 355: 21-30.

28 Farchi S, Forastiere F, Cesaroni G, Perucci CA. Environmental exposures and hospitalisation for respiratory 
conditions in children: a five year follow-up study in Rome, Italy. Occup Environ Med 2006; 63: 573-576.

29 Gehring U, Heinrich J, Kramer U, et al. Long-term exposure to ambient air pollution and cardiopulmonary mortality in women. Epidemiology 2006; 17: 545-551.

30 Rosenlund M, Berglind N, Pershagen G, Hallqvist J, Jonson T, Bellander T. Long-term exposure to urban air pollution and myocardial infarction. Epidemiology 2006; 17: 383-390.

31 Sunyer J, Jarvis D, Gotschi T, et al. Chronic bronchitis and urban air pollution in an international study. Occup Environ Med 2006; 63: 836-843.

32 Symons JM, Wang L, Guallar E, et al. A case-crossover study of fine particulate matter air pollution and onset of congestive heart failure symptom exacerbation leading to hospitalization. Am J Epidemiol 2006; 164: 421-433.

33 Rich DQ, Mittleman MA, Link MS, et al. Increased risk of paroxysmal atrial fibrillation episodes associated with acute increases in ambient air pollution. Environ Health Perspect 2006; 114: 120-123.

34 Wellenius GA, Schwartz J, Mittleman MA. Air pollution and hospital admissions for ischemic and hemorrhagic stroke among medicare beneficiaries. Stroke 2005; 36: 25492553.

35 Forastiere F, Stafoggia M, Tasco C, et al. Socioeconomic status, particulate air pollution, and daily mortality: Differential exposure or differential susceptibility. Am J Ind Med 2006; [Epub ahead of print PMID: 16960888].

36 Schlesinger RB, Künzli N, Hidy GM, Gotschi T, Jerrett M. The health relevance of ambient particulate matter characteristics: coherence of toxicological and epidemiological inferences. Inhal Toxicol 2006; 18: 95-125.

37 Clancy L, Goodman P, Sinclair H, Dockery DW. Effect of air-pollution control on death rates in Dublin, Ireland: an intervention study. Lancet 2002; 360: 1210-1214.
38 Bayer-Oglesby L, Grize L, Gassner M, et al. Decline of ambient air pollution levels and improved respiratory health in Swiss children. Environ Health Perspect 2005; 113: 1632-1637.

39 Heinrich J, Hoelscher B, Wichmann HE. Decline of ambient air pollution and respiratory symptoms in children. Am J Respir Crit Care Med 2000; 161: 1930-1936.

40 Heinrich J, Hoelscher B, Frye C, et al. Improved air quality in reunified Germany and decreases in respiratory symptoms. Epidemiology 2002; 13: 394-401.

41 Laden F, Schwartz J, Speizer FE, Dockery DW. Reduction in fine particulate air pollution and mortality: extended follow-up of the Harvard Six Cities Study. Am J Respir Crit Care Med 2006; 173: 667-672.

42 The European APHEIS Network. www.apheis.net. Date last updated: December 2006. Date last accessed: December 2006.

43 Boldo E, Medina S, LeTertre A, et al., on behalf of the Apheis group. Apheis: Health impact assessment of longterm exposure to PM2.5 in 23 European cities. Eur J Epidemiol 2006; 21: 449-458.

44 Johnson PR, Graham JJ. Fine particulate matter national ambient air quality standards: public health impact on populations in the north-eastern United States. Environ Health Perspect 2005; 113: 1140-1147.

45 The European Respiratory Society. Topics of interest to the ERS. Environment: air quality. www.ersnet.org/ers/ default.aspx?id=24678. Date last accessed: December 2006.

46 Air quality framework directive. http://ec.europa.eu/ environment/air/ambient.htm. Date last updated: December 2006.

47 Brunekreef B, Forsberg B. Epidemiological evidence of effects of coarse airborne particles on health. Eur Respir J 2005; 26: 309-318.

48 Rom WN, Samet JM. Small particles with big effects. Am J Respir Crit Care Med 2006; 173: 365-369. 